\title{
Social Taboos and Existing Practices Concerning Menstruation in the Nepalikhuti Area of Sivasagar District
}

\author{
Swastika Dutta ${ }^{1}$ and Jyoti Prasad Saikia ${ }^{2}$ \\ ${ }^{1}$ Research Scholar, Department of Sociology, Dibrugarh University, Assam, India \\ ${ }^{2}$ Professor, Department of Sociology, Dibrugarh University, Assam, India
}

\section{ABSTRACT}

Social taboos and practices are very deeply rooted in our society. In Hindu culture, menstruation which is a reproductive health element is considered religiously impure and ritually unclean. This particular paper is completely based on an empirical field study conducted in the Nepalikhuti area of Sivasagar District inhabited predominantly by Nepalese people. This paper looks into traditional practices and beliefs concentrated on "menstrual culture", "pre-puberty rituals" "first puberty rituals" that every young Nepali girl goes through, and "one of the festivals" which is associated with menstruation in the Nepalikhuti area. For this particular paper, I have been kept in front of the experience and perspectives of my respondences while arriving at the understanding whole "menstrual culture".

KEY WORDS: TABOO, WOMAN, SOCIETY, SOCIAL PRACTICES.

\section{INTRODUCTION}

The social taboos are created to alienate women from society during their menstruation, to isolate them from socio-religious activities, and to confine them within the domestic domain. The existing taboos made them believe that they are inferior to men and how this simple biological element has been reconstructed by society. The term "taboo" basically associates with anything that is forbidden. Social taboos are sanctioned by our society, social system, social rules, and regulation of course we as common people. Anthropologist Mary Douglas (2004), defines taboo as, "spontaneous coding practice which sets up a vocabulary of spatial limits and physical and verbal signals to hedge around vulnerable relations. It threatens specific dangers if the code is not respected. Some of the dangers which follow taboo-breaking spread harm indiscriminately on conduct. Feared contagion

Biosc Biotech Res Comm P-ISSN: 0974-6455 E-ISSN: 2321-4007
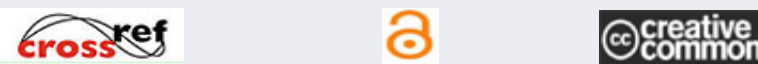

Identifiers and Pagination

Article Information

Year: 2021 Vol: 14 No (5) Special Issue

Received: $15^{\text {th }}$ Jan 2021

Pages: $141-144$

Accepted after revision: $30^{\text {th }}$ Mar 2021

This is an open access article under Creative

Commons License Attribn 4.0 Intl (CC-BY).

DOI: http://dx.doi.org/10.21786/bbrc/14.5/27 extends the danger of a broken taboo to the whole community."

When it comes to the menstrual taboo, there is a legend related to its origin in the Hindu Religion. According to Hindu Religious myths, Indra, who is considered as one of the most eminent deities among all the Vedic God, governs the whole universe especially the natural phenomena such as rains and season. The story narrative reveals that the king of heaven was accused of his sins, that is killing a brahmin (a high caste Hindu) and having illicit sexual acts with women during his quest. Therefore, to turn away from sin, all women were said to be punished through menstruation along with taboos. (U Prakash, 2017). According to this mythic context, menstrual blood is considered impure and dangerous because it was the result of Indra's curse.

Objectives: For this particular paper, my genuine attempt to explore the traditional social beliefs, practices, and taboos concentrated on Menstruation among the Nepali community of the Nepalikhuti area. High Nepali Brahmin Caste women such as Uppadhya, Sharma, and then low caste such as Rai, Limbu, Tamang, were selected randomly as a sample for my study. 


\section{METHODOLOGY}

Methodologically, the study takes a qualitative approach. This particular fieldwork was conducted by me in the Nepalikhuti area, a remote rural village located in Bihubar Siloni Area that comes under Bihubar local Panchayat and is inhabited predominantly by the Nepalese people. This study uses a qualitative descriptive study design.

Celebration of Bel Biya: A pre-puberty Rituals: Bel Bia is basically a unique cultural practice among the Pradhan caste of the Nepali community in the Nepalikhuti area. This particular ritual of "Bel Bia" distinguishes the Pradhan from other caste and has immense social and cultural significance, especially for young girls. This Bel Biya is considered to be one of the holiest and purest rituals among the Pradhan community. This ceremony is conducted before the girl attains puberty and the standard age for performing this pre-puberty ritual is considered from the age of five to seven.

In this ceremony, the virgin girls from the Nepali caste tie a marital knot with a Bel fruit i.e wood apple. Bel is a fruit, which is used for religious purposes but among Pradhans it is considered a sacred fruit. There are some religious as well as cultural beliefs associated to consider bel fruits as sacred ones, one of the reasons is that firstly the wood apple tree is associated with Lord Shiva. Henceforth the fruitwood apple is seen as an image of the deity. Secondly, Bel leaf and bel fruit are mandatory when it comes to worshipping lord shiva. Thirdly, bel fruit will never get rotten easily, the outer layer became hard day by day if it is being kept properly, which also they believe that her future husband will get long life and Bel fruit the symbolic husband is immortal.

Social significances of Bel Biya: In the Pradhan community, this Bel Biya is seen as a first marriage and with a human is a secondary one. The Bel fruit is considered as "Juwai" i.e son in law of family and young girls are supposed to keep the fruits for their entire life. This celebration links the girl with an eternal marriage with a lord shiva but in a form of Bel fruit. The most common reason for this practice is to protect the girl from the awful stigma of widowhood and also to protect the girl from malicious spirits. The Young girl is never considered a widow even after the death of her husband; because her first marriage with Bel is considered permanent and Bel fruit the symbolic husband is immortal. As Leela Dube in her work she has mentioned "what exactly to be a girl" lies in our socialisation process which inform her about her feminine quality and about her gender role in society.These puberty rituals brings consciousness about gender and gender role and by permorning these rituals actually grooms her to become a woman in near future.

Socio-Cultural Practices Concentrate on "First Puberty Rites": When a young girl gets her first puberty, she is restricted to stay in her native home rather she is immediately sent to seclusion on a neighbor or relative's house for week-long twenty-one days. This ritual is called "Lukuwai thuwa Niyom"” in the local language. A separate bed was used to set up on the floor in a different room. No one except her mother, an elder female of the family members is allowed to enter her room during these days. She is restricted to have fruits, non-veg items, and any milk product. The Entry of male members of the family even if father and brother are strongly prohibited. Neither the male voice nor the sight male member should reach by the mensurating girl. She has to be kept away from the sunlight because there is a strong belief associated with it they considered the sun as "lord Surya" and they worship the deity who represents prosperity and luck and wellness therefore in their first period of menstruation they were not allowed to see the sun, because they believe that it might bring bad luck if they came in contact with sunlight.

On the other hand, it's a mandatory restriction that menstruating girls were not allowed to drink milk or any milk products till twenty-one days. There are important religious significances attached to it. All the Nepali community people reside in the Nepalikhuti area, they worship cow as Ma Lakhmi, therefore in the first puberty rites menstruation, they were not allowed to drink cow milk or any milk products. Cows are regarded sacred and venerated in the Hindu religion especially among the Nepali community hence menstruating women are strictly prohibited not only to touch any milk products but also they are not allowed to enter cowshed either.

During the first puberty, the Young girl has to go through a ritual bath at the seven days of her menstruation. She took bath Early in the morning before the sun rises nearby the river Dikhow to fulfill one of the rites of her first puberty. The mother along with a few elder female members of the family escort her on this particular day. In some cases mother brings back her daughter and kept in their own house, sometimes she is sent back to the neighbor's house for another fourteen days. But keeping her in an isolated room with no sight of sun and men for twenty-one days is mandatory in their first puberty rites and which last up to twenty-one days. On the last day, she is given a ritual bath early in the morning which usually marks the end of rites of passage. As Arnold van, Gennep wrote about rites of passage to describe the transition of individuals from one social status to another. This first puberty ritual can also be looked at as a rite of passage because it also initiates the young girl into the categorized social group of fertile, sexually eligible women and these practices and rituals socialize a young girl to become a woman and make her ready for the new phase of womanhood. (Pator, 2019)

Socio-Cultural Practices and Taboos associated with Menstruation:

In the Nepalikhuti area, Menstruation is considered as an impure state called "Bahir huwa", "MC"," bahire niklinchu","bhitor humabo Nuwara" etc are different terminology that local people use while addressing their menstruation. Most Women indirectly express their menstrual status because speaking in public places about menstruation is a social taboo. There are many beliefs 
and practices are linked up with menstrual culture. The state of pollution stays with every young girl and woman for the whole menstruating period for five to seven days every month. The performance of taboos is equivalent to abide by the prescribed rules. Young girl or women must stay within the confined room, she is not allowed do to any household activity, because while menstruating if they touch any tangible and intangible items, it automatically becomes impure too. Married women were not supposed to wear vermilion on their forehead till the third day of menstruating days, at the fourth day onwards after the bath she can wear vermilion. she can enter the kitchen and cook meals for the family members after four days because the kitchen is considered as a Goddess Lakhis abode so entering in the kitchen is strictly prohibited till the third days. She is purely forbidden to do any religious activity till her seventh day of the period. The ritual bath on her third day symbolizes that she has cleansed herself from all the polluting dirt.

Festival of Teez and beliefs related to "Menstruation Culture': Teej is the festival and ritual especially for the Nepali Hindu brahmin women, celebrated on the bhado mah of Assamese calendar (august in English calendar). It starts from Krishna's Janmashtami up to fourteen days. This festival is celebrated in different regions differently but the mythical aspect of this festival is the same. In Hindu Mythology, it is believed that Goddess Parvati and Lord Shiva were united on this day and it is considered to be an auspicious day and it is supposed that whosoever remembers her on this day will be blessed with a happy married life and all her desires will be fulfilled. Even today, women commemorate this mythological event by observing a 'Nirjala Vrata' (fasting without drinking water) for their husband's well-being and long life. (Ganga, 1999). In this particular festival married daughters and sisters are invited to their parent's home to celebrate Teej festive, in which they do fast, worship Lord Shiva, sing songs and perform dances. The celebration varies due to diverse geographical locations.

Now many questions arise why this festival is related to menstrual culture? It, because there are significant cultural and religious rituals, are attached to the Teez festival in the Nepalikhuti area. During the time of two-week celebration, on the auspicious occasion of Panchami, the fifth-day rituals are purely associated with the menstruation of women. According to the Hindu myth woman's menstruation period is a type of cursed period. In this period if a woman knowingly or unknowingly touches any materials of the house that will be the greatest sin in her life. A woman must celebrate Panchami and do all the rites and rituals to redeem herself from menstrual sin. There is a strong belief among local people of this area that, If a woman does not worship in the Teez Panchami, she can never be redeemed from her menstrual sin in life.

On this day, in early in the morning before the sun rises, devoted women take bath in nearby the Dikhow river, and worship lord shiva. They collect mud from elephant footprints, from the river Dikhow and amla tree, mud with cow dung and apply over their body. This bath should be taken from head to toe applying and washing each body part with the collecting mud separately. They build a Shiva Linga in the bathing place. Along with the bathing processes, the rituals of Panchami are over. The significance of bathing is believed to have made the menstruated body a holy one. There are local herbs call "Dattoiun", women during the Panchami have to wash their teeth with Dattiun 365 times and by each 365 Dattiuns, they have to chew to redeemed their menstrual sin.

Rituals of Purification: Before the beginning of, any ceremony whether it Bel Biya, the first rites of puberty, or Teez festivals young girls and women must be purified with sacred products of the cow such as cow dung, cow urine, and the holy water of the nearby river, and tulsi petals are sprinkled over her head, to remove all her past menstrual sins. River Dikhow plays a very significant role among the Nepali community because every ritual or festival either took place nearby the river or water is one of the mandatory products for purification. During the first puberty rites, young girls must offer prayers to the river as "Ganga ma" ask for misery for polluting her water while bathing and washing menstrual cloths. River Dikhow plays a very significant role in terms of the purification of women because most of the rites and rituals took place nearby the river bank. Women's menstruation and menstrual practices were not only regarded as a rite of passage marking adulthood but also as a "rite of passage to the spiritual" and important to the balance and well-being of the community and earth itself. (Markstrom, 2008).

\section{CONCLUSION}

Construction of menstruation culture are built by our surrounding socio-cultural environment. Although there are many cultural representations of blood, ranging from family and kinship, to violence and war, menstrual blood is almost always positioned negatively. (Bramwell, 2001). Menstrual practices will remain in our society because firstly, A section of women particularly those who belong to the upper caste, themselves considered that these social practices and rituals are necessary to maintain their culture in the purest form and to balance the caste hierarchy and The brahmin caste, has another way of explaining the need for the existence of such taboos i.e. its preserve their cultural belief and practices and they wanted to teach next generation to continue this culture Secondly, other lower castes such as Rai, Limbu, Thapaa, for them it's just a biological process that every woman go through for a certain period, its cultural shock to see other castes maintain their menstrual culture.

They never practice such pre-puberty, Teez festival related with menstruation, their belief and practices are only confined to not participate any religious activities. For them, it's a society and upper caste people that such practices and beliefs are being created otherwise it's just a normal biological fact that every woman goes 
through. Thirdly, this culture of menstruation supported by own societal norms, religion, caste system, these traditional cultural beliefs system, and practices has influenced women's life and their participation and has also augmented the position of the caste hierarchy system in the mindset of Nepali society. After the fieldwork, I observe that religion and culture can never be placed in any isolation form, it goes together and hands in hand. The taboos and social practices come over a celebration for Nepali community people in the Nepalikhuti area.

\section{REFERENCES}

Baldy, R C (2016). Mini-k'iwhe:n (For That Purpose -I Consider Things0 : (Re) writing and (Re) righting Indigenous Menstrual Practices to Intervene on contemporary Menstrual Discourse and Politics of taboo. Cultural studies critical methodologies. 1(9),1-9.

Das, M. (2008). Menstruation as Pollution: Taboos in Simlitola. Indian Anthropological Association, 38 (2),29-42.

Hawkey J A, Ussher M J, Perz J, Metusela C (2016). Experience and Construction of Menarche and Menstruation Among Migrant and Refugee Women. Sage publication.1-18.
Hoskins J. (2002). Blood Mysteries: beyond Menstruation as pollution. Ethology 41(4), 299-301.

Mangar R. (2019). Bel Bibaha Among the Newars and its Social Significance. Social trends,journal of department of sociology of north Bengal university.6220-229.

Patar, M. (2019). Tuloni; Experience and Negotiations around Womanhood in Assamese Society. Exploration, 3(1), 65-88.

Selvi T K, Ramachandran S, (2012). Socio-cultural taboos concerning Menstruation : A Micro Level study in the Cuddalore District of Tamil Nadu,India. international journal of scientific and research publication, 2(8).

Sridhar N. (2019). The Sabrimala Confusion Menstruation Across Culture A Historical Perspective. Vitasta Publishing Pvt Ltd.

Thomas M. E. (2007). Menstruation Discrimination; The Menstrual Taboo as a Rhetorical function of Discourse in the National and international advances of women's rights. Contemporary Argumentation and Debate, 28, 65-90.

Upadhya P. (2017). Menstruation and Pollution Taboos and Gender Based Violence in Western Nepal. The Nehu Journal, 15(2), 101-111. 